\title{
Psychological Distress Amongst Health Workers and the General Public During the COVID-19 Pandemic in Saudi Arabia
}

This article was published in the following Dove Press journal: Risk Management and Healthcare Policy

\author{
Mohammed Khaled \\ Al-Hanawi iD ' \\ Martin Limbikani Mwale (D) ${ }^{2}$ \\ Noor Alshareef \\ Ameerah MN Qattan (D) \\ Khadijah Angawi ' \\ Rasha Almubark (iD) 3,4 \\ Omar Alsharqi \\ 'Department of Health Services and \\ Hospital Administration, Faculty of \\ Economics and Administration, King \\ Abdulaziz University, Jeddah 80200, Saudi \\ Arabia; ${ }^{2}$ Department of Economics, \\ Faculty of Economic and Management \\ Sciences, University of Stellenbosch, \\ Cape Town, South Africa; ${ }^{3}$ Research and \\ Studies Department, Saudi Food and \\ Drug Authority, Riyadh, Saudi Arabia; \\ ${ }^{4}$ Sharik Association for Health Research, \\ Riyadh, Saudi Arabia
}

Background: The rapid spread of COVID-19 worldwide has confined millions of people to their homes and has caused a substantial degree of psychological distress. This study aims to investigate the psychological distress impact of the COVID-19 pandemic among the Saudi population.

Methods: This is a cross-sectional study, using data collected from 3036 participants via an online self-reported questionnaire. The psychological distress was constructed using the COVID-19 Peritraumatic Distress Index to classify individuals in the sample as having normal, mild or severe distress levels. The study used descriptive analysis and multinomial logistic regressions to examine the sociodemographic factors associated with psychological distress levels during the COVID-19 pandemic.

Results: The evidence showed that $40 \%$ of the Saudi population are distressed due to COVID-19, of whom approximately $33 \%$ are mildly distressed, while $7 \%$ are severely distressed. The distress levels are particularly high amongst the young, females, private sector employees and health workers, especially those working on the frontline.

Conclusion: The COVID-19 pandemic is associated with increased distress amongst people living in Saudi Arabia. In support of evidence found in other countries, the study has established that the distress levels vary across different sociodemographic characteristics. Therefore, limiting people's psychological damage demands both medium- and long-term policy strategies, which include mapping the rates of stress and anxiety for effective psychological treatment allocation and establishing innovative online methods of heightening people's mental wellbeing.

Keywords: COVID-19, distress, health workers, psychological, public, Saudi Arabia

\section{Introduction}

Coronavirus disease 2019 (COVID-19) is a respiratory syndrome, amongst a larger family of ribonucleic acid (RNA) viruses, that has infected humans, causing unprecedented numbers of deaths and substantial psychological distress across the globe. ${ }^{1-3}$ COVID-19 emerged in Wuhan, China at the end of 2019 and spread to other countries, leading the World Health Organisation (WHO) to declare COVID19 a global health emergency of international concern. The WHO emphasised the importance of compliance with infection control standards. ${ }^{4}$ Not only were the obvious practices of hygiene and use of hygiene equipment, such as facemasks, important but, also, limiting personal contact through social distancing became the gold standard. .,6 $^{5}$
Correspondence: Mohammed Khaled Al-Hanawi

Department of Health Services and Hospital Administration, Faculty of Economics and Administration, King Abdulaziz University, Jeddah 80200, Saudi Arabia

Email mkalhanawi@kau.edu.sa 
In response, several countries have implemented decisive measures to contain the spread of the disease, which include the imposition of nationwide lockdowns. China was the first country to implement a successful lockdown to prevent the further spread of COVID-19. ${ }^{7}$ Notwithstanding the resultant mitigation of the pandemic in China, there has been a deterioration in most Chinese residents' psychological wellbeing under the lockdown. ${ }^{8-10}$ The adverse psychological impact includes acute stress disorder, insomnia, posttraumatic symptoms and depression. ${ }^{11}$ Moreover, recent evidence reveals that $35 \%$ of the Chinese population were psychologically distressed. ${ }^{12}$

The distress caused by COVID-19 is arguably not limited to China because the factors that could lead to this psychological state are common. For instance, the knowledge of coronavirus biology and transmission is still limited, which increases panic due to the uncertainty of its spread. ${ }^{7}$ In addition, there is a global absence of a vaccine to control COVID-19, leading to unrest about its containment. ${ }^{13}$ Moreover, globalisation and increased access to information in the current era make such worrying insights relating to uncertainty easily transferable, causing increased psychological distress, including fear and anxiety, amongst the general public. ${ }^{14-16}$

The WHO issued a COVID-19 guideline on mental health and psychological distress in an effort to support people's mental and psychological wellbeing during this outbreak. ${ }^{2}$ Nevertheless, empirical evidence on the distribution of psychological distress across the public due to COVID-19 remains sparse. Therefore, this study aims to investigate the impact of COVID-19 on the psychological wellbeing among Saudi adults amid the unprecedented lockdown. Preventive measures, such as lockdown, disrupt normal life activities, which could generate boredom and stress. Moreover, the limited access to outdoor leisure, combined with the uncertainty of an effective remedy to contain the pandemic, could increase distress. However, these potential negative effects could generate different levels of distress conditional on people's sociodemographic characteristics. For instance, the demand for outdoor activities could be different between older people and the young, while fears relating to the lack of available treatment for the pandemic could also differ depending on whether one works in healthcare services or not. These issues demand adequate attention and, therefore, the study also examines the association between different sociodemographic characteristics and psychological distress due to COVID-19 using data from the Kingdom of Saudi Arabia (KSA).

KSA has become a compelling case in understanding how COVID-19 has caused psychological distress amongst health workers and the general public for the following reasons. First, KSA currently has the largest confirmed number of cases in the Arabian Gulf countries, which means that the likelihood of pressure on the health system and fear of infection, which could cause distress, remain high. Second, despite the potential for increased psychological distress in KSA, no study has been conducted to identify the groups that might be suffering the most in terms of distress due to the pandemic. Third, the Arabian Gulf region has specific unique characteristics, such as a natural resource-financed health system, ${ }^{17}$ that would necessitate that the public health response to COVID-19 be different from the rest of the world, hence the demand for special academic attention. Finally, as the Arabian Gulf countries have similar backgrounds, culture and religion and are facing similar challenges, this study on KSA could inform policy design to mitigate COVID-19 related distress in the entire region.

\section{Materials and Methods Study Design and Sample}

This study uses data from a cross-sectional survey that was conducted in Saudi Arabia from 3 May to 8 May 2020, using a validated self-reported survey. The survey used the COVID-19 Peritraumatic Distress Index (CPDI) selfreported questionnaire that was originally employed by a study in China to survey peritraumatic psychological distress during the epidemic. ${ }^{12}$ The Shanghai Mental Health Centre verified the content validity of the CPDI as fit to be used in collecting the COVID-19 distress information. The questionnaire is originally in English. R.A and A.M.N.Q translated the questions into Arabic, while M.K.A and O.A translated it back to English to ensure that the translation preserved the meaning captured by the original English version. The survey then used the Arabic text to administer the study.

Data were collected online, using SurveyMonkey, targeting individuals living in KSA. A link to the survey was distributed to respondents via social media, such as Twitter and WhatsApp groups. The link was also posted on the King Abdulaziz University website. Online informed consents were obtained before proceeding with the questions. The informed consent provided two options of "yes", for 
those who volunteered to partcipate in the study, and "no", for those who did not wish to participate. Only those who selected the affirmative response and confirmed that they were above the age of 18 years were taken to the questionnaire page to complete the survey. The respondents were clearly informed about the study's aim and objectives and that they were free to withdraw at any time, without giving a reason, and that all information and opinions provided would be anonymous and confidential.

\section{Measurement Tool and Data Analysis}

The questionnaire consisted of two main sections. The first section gathered information on the respondents' sociodemographic characteristics, including age, gender, marital status, education level, nationality, work status, whether the participants are health workers and, if so, whether they were working on the frontline to face the new coronavirus pandemic. The second section collected information on self-perceived psychological distress in relation to the COVID outbreak.

\section{Dependent Variable (Psychological Distress Assessment)}

In this paper, psychological distress is defined as an unpleasant feeling or emotion that affects a human being's general functioning and could induce negative feelings of self, others and the environment. ${ }^{18}$ Participants were asked to respond to 24 questions that had five scaled responses to assess their psychological distress and the responses were used to construct a CPDI. The responses to these questions include $0=$ never, $1=$ occasionally, $2=$ sometimes, $3=$ often and $4=$ most of the time. The questions included those on the frequency of anxiety, depression, specific phobias, cognitive change, avoidance and compulsive behaviour, physical symptoms and loss of social functioning since the appearance of the COVID-19 pandemic. These questions encompass the diagnostic guidelines for stress disorders and phobias specified in the International Classification of Diseases, 11th Revision. $^{12}$

To construct the CPDI, we summed the codes of the responses of the 24 questions, meaning that the respondents' scores could range from 0 to 96 . A base count of 4 was added to all respondents to enable the maximum of the standard 100 for a CPDI. The addition of the base, which was also done in a recent study on the effects of COVID-19 on distress in China, ${ }^{12}$ allows our results to be compared to previous studies that used 100 by increasing the base without changing the gradient of the effects. The CPDI was then classified to obtain the levels of distress, as follows: a CPDI score between 0 and 28 indicates normal levels, a CPDI score between 29 and 52 indicates that the participant is mildly distressed and a CPDI score between 53 and 100 means that the respondent is severely distressed. Items were evaluated for internal reliability, using Cronbach's $\alpha$. The Cronbach's alpha coefficient was $0.91(\mathrm{p}<0.001)$, indicating internal reliability. ${ }^{19}$

\section{Independent Variables}

For the sociodemographic variables, the age variable was divided into categories: 18 to 29 (reference category), 30 to 39,40 to 49,50 to 59 and 60 or above. Gender was coded as a dummy variable with 1 for male and 0 for female. Marital status was captured as binary and a value of 1 was used for married and 0 for otherwise. Education was categorised into high school or below (reference category), college/university degree and postgraduate degree. Nationality was coded as a dummy variable, with 1 for Saudi national and 0 for non-Saudi. Work status was divided into categories including government employee (reference category), private sector employee, retiree, self-employed, student and unemployed. Health worker was coded as a dummy variable with 1 if the respondent is a health worker and 0 for otherwise. Frontline health worker against COVID-19 was also coded as 1 for participants who were frontline health workers and 0 for otherwise.

\section{Statistical Analysis}

Descriptive statistics were used to analyse the general data. The respondents' characteristics were classified by their psychological distress through the three distress categories and their mean and percentage composition presented per distress group. The study used a statistical model corrected for multiple comparisons by the Bonferroni procedure, which divides the $0.05 \mathrm{p}$-value by the number of comparisons to minimise type 1 errors. ${ }^{20}$ The method allows us to present the statistically significant differences across the three distress categories with respective p-values depicted.

Multinomial logistic regressions were used with CPDI as the dependent variable to examine the factors associated with normal, mild and severe distress due to COVID-19, while the sociodemographic characteristics are the independent variables. The CPDI is coded with three groups -1 for normal distress (reference category), 2 for mild distress and 3 for severe distress. Since the logistic coefficients are composite numbers, we obtained the marginal effects 
using the first derivative method and all the results presented in the paper are the actual probabilities. Knowing that the degree of exposure to COVID-19 could generate variations in the distress levels, the study, besides presenting the full sample probabilities, includes a subsample analysis that looks only at health workers. All analyses were conducted using STATA 15.1 software (StataCorp LP, Texas, USA).

\section{Ethical Approval}

All procedures performed in this study involving human participants complied with the institutional and/or national research committee ethical standards and the 1964 Helsinki declaration, and subsequent amendments, or equivalent ethical standards. The study was designed and conducted in accordance with the ethical principles established by King Abdulaziz University and, therefore, ethical approval was obtained from the Biomedical Ethics Research Committee, Faculty of Medicine, King Abdulaziz University (Ref228-20).

\section{Results}

\section{Sociodemographic Characteristics and Distress Level}

Table 1 shows the results of the descriptive analysis. In total, 3036 participants, including $950(31.35 \%)$ health workers, of which $449(14.8 \%)$ were frontline health workers, with the remaining 2086 (68.7\%) being the general public, participated in the study from the 13 administrative regions in KSA. Of the participants, $30.9 \%$ were aged between 18 and 29 years, $50.1 \%$ were males and $62.7 \%$ were married. In terms of education, $26 \%$ of the participants were educated at the high school level or below, while $54.3 \%$ had completed college or university degrees and $19.6 \%$ had completed a postgraduate degree.

The distress distribution across the entire sample shows that, of the 3036 individuals, 1819 (59.9\%) were normal, 999 (32.9\%) were mildly distressed and 218 (7.2\%) were severely distressed. Amongst health workers, the proportion of respondents as a percentage of the total sample increased as we moved from normal (28.9\%), through mild (33.7\%), to severe (39.9\%) distress. The result is statistically significant $(\mathrm{p}<0.01)$, which provides preliminary evidence that health workers are at greater risk of psychological distress relative to non-health workers. A similar statistically significant trend is observed for frontline health workers, with the percentage growing from normal (13.4\%), through mild $(15.5 \%)$, to severe (24.3\%) distress.

Furthermore, there are no statistical differences in distress levels for people in the age range of 18 to 29 , while those between 30 and 39 years have a statistically significant increased trend in the percentage of people as we move from normal (35.8\%), through mild (38.6\%), to severe distress $(46.8 \%)$. On the contrary, the age group 40 to 49 has a decreasing trend in the level of distress from normal $(23.4 \%)$, through mild $(18.1 \%)$, to severe $(13,3 \%)$. Those between the ages of 50 and 59 follow, with a decreasing distress incidence of $9.8 \%, 7 \%$ and $6 \%$ for normal, mild and severe distress, respectively. People aged 60 or above also show a decreasing trend, from $3.1 \%$ to $2.6 \%$ to $0.9 \%$ for normal, mild and severe distress levels, respectively. The age distress statistics reveal that the young, and particularly those between 30 and 39, face the largest psychological distress risk as a result of COVID-19. At the same time, older people are at the lowest risk for this mental disturbance.

Across gender, males show a decreasing trend from normal $(53.2 \%)$, through mild (45.0\%) to severe (42.2\%) distress levels. On the contrary, females show an increasing trend from normal (46.8\%), through mild (55\%) to severe $(57.8 \%)$ distress, with the results illustrating that the largest distress burden falls on females relative to males. There are no statistical differences in distress trends across education and nationality. Concerning employment status, only the retired, with a trend of 5.2\% normal, $3 \%$ mild and $2.3 \%$ severe distress, and the self-employed, with a trend of $4.3 \%$ normal, $3.6 \%$ mild and $1.8 \%$ severe distress, become statistically significant.

\section{The Analysis of Distress Levels}

Table 2 presents the marginal effects of the multinomial logistic regression results for the entire sample. The presented estimates, therefore, are the probabilities of belonging to a particular CPDI level. Being a health worker is significantly associated with an increased probability of being mildly distressed by 0.041 and that of being severely distressed by 0.028 . Across ages, there is a significant reduction in the probability of 40 to 49 year olds being mildly and severely distressed by 0.078 and 0.032 , respectively, while those in the age range of 50-59 associate with only a reduction in mild distress by 0.082 . As these cohorts are compared to a reference group of the young, between the ages of 18 to 29 , the evidence concurs with what was observed in the sociodemographic descriptive 
Table I Sociodemographic Characteristics and Distress Levels

\begin{tabular}{|c|c|c|c|c|c|}
\hline & Total & Normal & Mild & Severe & P-value \\
\hline Overall & 3036 & $1819(59.9)$ & $999(32.9)$ & $218(7.2)$ & \\
\hline \multicolumn{6}{|l|}{ Health worker } \\
\hline Yes & $950(31.3)$ & $526(28.9)$ & $337(33.7)$ & $87(39.9)$ & $0.007^{* * *}$ \\
\hline No & $2086(68.7)$ & |293(7|.I) & $662(66.3)$ & $13 \mid(60.1)$ & $0.007 * * *$ \\
\hline \multicolumn{6}{|l|}{ Frontline health worker } \\
\hline Yes & $449(14.8)$ & $244(13.4)$ & $155(\mid 5.5)$ & $53(24.3)$ & $0.001 * * *$ \\
\hline No & $2587(85.2)$ & $1575(86.6)$ & $844(84.5)$ & $165(75.7)$ & $0.001 * * *$ \\
\hline \multicolumn{6}{|l|}{ Age } \\
\hline 18 to 29 & $938(30.9)$ & $508(27.9)$ & $336(33.6)$ & $72(33)$ & 0.328 \\
\hline 30 to 39 & $1129(37.2)$ & $65 I(35.8)$ & $386(38.6)$ & $102(46.8)$ & $0.005^{* * *}$ \\
\hline 40 to 49 & $625(20.6)$ & $426(23.4)$ & $181(18.1)$ & $29(13.3)$ & $0.001 * * *$ \\
\hline 50 to 59 & $26 I(8.6)$ & $178(9.8)$ & $70(7.0)$ & $13(6)$ & $0.06 I^{*}$ \\
\hline$\geq 60$ & $82(2.7)$ & $56(3.1)$ & $26(2.6)$ & $2(0.9)$ & $0.038 * *$ \\
\hline \multicolumn{6}{|l|}{ Gender } \\
\hline Male & $152 \mid(50.1)$ & $968(53.2)$ & $450(45.0)$ & $92(42.2)$ & $0.015 * *$ \\
\hline Female & $1515(49.9)$ & $85 I(46.8)$ & $549(55.0)$ & $126(57.8)$ & $0.015 * *$ \\
\hline \multicolumn{6}{|l|}{ Marital status } \\
\hline Married & $1904(62.7)$ & $1161(63.8)$ & $610(61.1)$ & $135(61.9)$ & 0.754 \\
\hline Unmarried & $1132(37.3)$ & $658(36.2)$ & $389(38.9)$ & $83(38.1)$ & 0.754 \\
\hline \multicolumn{6}{|l|}{ Education } \\
\hline High school education or below & $789(26.0)$ & $460(25.3)$ & $267(26.7)$ & $6 I(28)$ & 0.480 \\
\hline College/University degree & $|65|(54.3)$ & $990(54.4)$ & $540(54.1)$ & $123(56.4)$ & 0.547 \\
\hline Postgraduate degree & $596(19.6)$ & $369(20.3)$ & $192(19.2)$ & $34(15.6)$ & 0.108 \\
\hline \multicolumn{6}{|l|}{ Nationality } \\
\hline Saudi & 2836(93.4) & I704(93.7) & $924(92.5)$ & 204(93.6) & 0.932 \\
\hline Non Saudi & $200(6.6)$ & $115(6.3)$ & $75(7.5)$ & $14(6.4)$ & 0.932 \\
\hline \multicolumn{6}{|l|}{ Employment status } \\
\hline Government sector employee & $1354(44.6)$ & $839(46.1)$ & $4 \mid 8(4 \mid .8)$ & $95(43.6)$ & 0.704 \\
\hline Private sector employee & $498(16.4)$ & $273(15)$ & $185(\mid 8.5)$ & $39(17.9)$ & 0.524 \\
\hline Retiree & $|3|(4.3)$ & $95(5.2)$ & $30(3.0)$ & $5(2.3)$ & $0.025 * *$ \\
\hline Self-employed & $118(3.9)$ & $78(4.3)$ & $36(3.6)$ & $4(1.8)$ & $0.052 *$ \\
\hline Student & $43 I(14.2)$ & $240(\mid 3.2)$ & $155(\mid 5.5)$ & $36(16.5)$ & 0.334 \\
\hline Unemployed & $504(16.6)$ & $295(16.2)$ & $175(17.5)$ & $39(17.9)$ & 0.627 \\
\hline
\end{tabular}

Notes: Percentages in parentheses. ${ }^{* * *} \mathrm{p}<0.01$, ${ }^{* *} \mathrm{p}<0.05,{ }^{*} \mathrm{p}<0.1$.

analysis that older people are less susceptible to distress relative to younger people.

Amongst these people, males are less likely to be mildly distressed by 0.063 and less severely distressed by 0.023 indicating that the reference category, female, is at a greater risk of being distressed. With regard to employment status, only private sector employees are more likely to be mildly distressed, by 0.059 , relative to the omitted category of government sector employees. All the other employment categories are not significantly different in their susceptibility to distress in comparison to the government sector employees. The education variable shows that only postgraduates relate to a 0.029 reduction in the probability of being severely distressed, in relation to the comparison group of the high school or below education level. The results also show that nationality does not matter in terms of distress caused by the pandemic.

The results also revealed that, amongst all social demographic characteristics, only age particularly that of 40 to 49 , gender, people with postgraduate qualifications and 
Table 2 The Marginal Effects of Sociodemographic Characteristics on Distress

\begin{tabular}{|c|c|c|c|}
\hline \multirow[t]{2}{*}{ Dependent Variable: CPDI } & ( 1 ) & (2) & (3) \\
\hline & Normal & Mild & Severe \\
\hline Health worker & $\begin{array}{l}-0.069 * * * \\
(0.020)\end{array}$ & $\begin{array}{l}0.041 * * \\
(0.019)\end{array}$ & $\begin{array}{l}0.028 * * * \\
(0.010)\end{array}$ \\
\hline 30 to 39 years & $\begin{array}{l}0.021 \\
(0.027)\end{array}$ & $\begin{array}{l}-0.033 \\
(0.026)\end{array}$ & $\begin{array}{l}0.012 \\
(0.014)\end{array}$ \\
\hline 40 to 49 years & $\begin{array}{l}0.110 * * * \\
(0.032)\end{array}$ & $\begin{array}{l}-0.078^{* *} \\
(0.031)\end{array}$ & $\begin{array}{l}-0.032 * \\
(0.018)\end{array}$ \\
\hline 50 to 59 years & $\begin{array}{l}0.107 * * * \\
(0.04 I)\end{array}$ & $\begin{array}{l}-0.082^{* *} \\
(0.040)\end{array}$ & $\begin{array}{l}-0.026 \\
(0.024)\end{array}$ \\
\hline$\geq 60$ years & $\begin{array}{l}0.056 \\
(0.072)\end{array}$ & $\begin{array}{l}0.017 \\
(0.068)\end{array}$ & $\begin{array}{l}-0.073 \\
(0.054)\end{array}$ \\
\hline Male & $\begin{array}{l}0.086 * * * \\
(0.020)\end{array}$ & $\begin{array}{l}-0.063^{* * *} \\
(0.019)\end{array}$ & $\begin{array}{l}-0.023 * * \\
(0.011)\end{array}$ \\
\hline Married & $\begin{array}{l}-0.048 * * \\
(0.022)\end{array}$ & $\begin{array}{l}0.032 \\
(0.022)\end{array}$ & $\begin{array}{l}0.016 \\
(0.012)\end{array}$ \\
\hline College/University degree & $\begin{array}{l}0.030 \\
(0.022)\end{array}$ & $\begin{array}{l}-0.022 \\
(0.021)\end{array}$ & $\begin{array}{l}-0.008 \\
(0.011)\end{array}$ \\
\hline Postgraduate degree & $\begin{array}{l}0.042 \\
(0.028)\end{array}$ & $\begin{array}{l}-0.013 \\
(0.027)\end{array}$ & $\begin{array}{l}-0.029 * \\
(0.016)\end{array}$ \\
\hline Saudi national & $\begin{array}{l}0.034 \\
(0.036)\end{array}$ & $\begin{array}{l}-0.034 \\
(0.034)\end{array}$ & $\begin{array}{l}-0.000 \\
(0.019)\end{array}$ \\
\hline Private sector employee & $\begin{array}{l}-0.067 * * \\
(0.027)\end{array}$ & $\begin{array}{l}0.059 * * \\
(0.026)\end{array}$ & $\begin{array}{l}0.008 \\
(0.014)\end{array}$ \\
\hline Retiree & $\begin{array}{l}0.075 \\
(0.059)\end{array}$ & $\begin{array}{l}-0.077 \\
(0.058)\end{array}$ & $\begin{array}{l}0.002 \\
(0.036)\end{array}$ \\
\hline Self-employed & $\begin{array}{l}0.041 \\
(0.050)\end{array}$ & $\begin{array}{l}0.003 \\
(0.047)\end{array}$ & $\begin{array}{l}-0.044 \\
(0.035)\end{array}$ \\
\hline Student & $\begin{array}{l}-0.017 \\
(0.036)\end{array}$ & $\begin{array}{l}0.007 \\
(0.035)\end{array}$ & $\begin{array}{l}0.009 \\
(0.019)\end{array}$ \\
\hline Unemployed & $\begin{array}{l}0.002 \\
(0.030)\end{array}$ & $\begin{array}{l}-0.000 \\
(0.029)\end{array}$ & $\begin{array}{l}-0.001 \\
(0.016)\end{array}$ \\
\hline Observations & 3036 & 3036 & 3036 \\
\hline
\end{tabular}

Notes: Standard errors in parentheses. ${ }^{* * *} p<0.01,{ }^{* *} p<0.05,{ }^{*} p<0.1$.

health workers significantly relate to the severely distressed category. Furthermore, being a health worker has the highest probability $(0.028)$ of being severely distressed with the highest level of significance $(\mathrm{p}<0.01)$ relative to the rest in the group. Moreover, the descriptive statistics in Table 2 revealed that health workers have an increasing trend of distress, from mild to severe, relative to non- health workers and, therefore, health workers could be at relatively higher risk of distress compared to the rest of the population. The result warrants further investigation into the different characteristics of health workers that correlate with the various levels of distress. The study interrogated these health worker correlates of distress by examining the relationship between sociodemographic variables and distress amongst only health workers and the results are presented in Table 3.

Table 3 presents the estimates of the sample for health workers. Knowing that not all health workers are working in close contact with the COVID-19 infected, a variable that separates ordinary health workers and frontline workers is included in the analysis as these two groups could have different levels of distress due to their variations in exposure to the pandemic. Column (1) shows that being frontline health worker increases the probability of severe distress, by 0.049 . Health workers who are between the ages of 30 to 39 are less likely to be mildly distressed, by 0.074, while those between the ages of 40 to 49 are less susceptible to mild distress by 0.154 . In addition, those in the age range of 50 to 59 have a reduced probability, by 0.263 , of being mildly distressed. The age output reveals that, relative to the reference category of 18 to 29 years old, older people are less likely to be distressed. Furthermore, male health workers are less likely to be severely distressed, by 0.046 , while students are the only employment category less likely to be mildly distressed, by 0.113 . The results reveal that, amongst health workers, education and nationality do not correlate with distress due to COVID-19.

\section{Discussion}

KSA reported its first case of COVID-19 on 2 March 2020 and, by 14 May 2020, the number was at 44,830 , which was the highest in the Arabian Gulf states. Throughout the history of emerging pandemics, it has been documented that there is a strong association between a pandemic event and individuals' psychological distress. Several studies have investigated the impact of pandemics on psychological distress. The evidence dates back to the 1918 Spanish Flu pandemic, which resulted in psychiatric complications. $^{21}$ With the surge in the prevalence of COVID-19, and the quarantine restrictions, anxiety and stress levels rise. ${ }^{22}$ Thus, this study attempts to understand the impact of COVID-19 on the psychological distress among the Saudi population during the pandemic. Understanding this impact is central in crafting effective 
Table 3 The Marginal Effects of the Sociodemographic Characteristics on Distress Amongst Health Workers

\begin{tabular}{|c|c|c|c|}
\hline \multirow[t]{2}{*}{ Dependent Variable: CPDI } & (I) & (2) & (3) \\
\hline & Normal & Mild & Severe \\
\hline Frontline health worker & $\begin{array}{l}-0.017 \\
(0.033)\end{array}$ & $\begin{array}{l}-0.033 \\
(0.032)\end{array}$ & $\begin{array}{l}0.049 * * \\
(0.020)\end{array}$ \\
\hline 30 to 39 & $\begin{array}{l}0.062 \\
(0.048)\end{array}$ & $\begin{array}{l}-0.074 * \\
(0.045)\end{array}$ & $\begin{array}{l}0.011 \\
(0.028)\end{array}$ \\
\hline 40 to 49 & $\begin{array}{l}0.165 * * * \\
(0.058)\end{array}$ & $\begin{array}{l}-0.154^{* * *} \\
(0.056)\end{array}$ & $\begin{array}{l}-0.012 \\
(0.035)\end{array}$ \\
\hline 50 to 59 & $\begin{array}{l}0.275^{* * *} \\
(0.089)\end{array}$ & $\begin{array}{l}-0.263^{* * *} \\
(0.090)\end{array}$ & $\begin{array}{l}-0.012 \\
(0.052)\end{array}$ \\
\hline$\geq 60$ & $\begin{array}{l}0.036 \\
(0.153)\end{array}$ & $\begin{array}{l}-0.033 \\
(0.145)\end{array}$ & $\begin{array}{l}-0.003 \\
(0.095)\end{array}$ \\
\hline Male & $\begin{array}{l}0.067^{*} \\
(0.035)\end{array}$ & $\begin{array}{l}-0.021 \\
(0.034)\end{array}$ & $\begin{array}{l}-0.046 \text { ** } \\
(0.021)\end{array}$ \\
\hline Married & $\begin{array}{l}-0.000 \\
(0.039)\end{array}$ & $\begin{array}{l}-0.035 \\
(0.037)\end{array}$ & $\begin{array}{l}0.035 \\
(0.023)\end{array}$ \\
\hline College/University degree & $\begin{array}{l}0.048 \\
(0.042)\end{array}$ & $\begin{array}{l}-0.048 \\
(0.040)\end{array}$ & $\begin{array}{l}0.000 \\
(0.024)\end{array}$ \\
\hline Postgraduate degree & $\begin{array}{l}0.071 \\
(0.048)\end{array}$ & $\begin{array}{l}-0.044 \\
(0.046)\end{array}$ & $\begin{array}{l}-0.027 \\
(0.029)\end{array}$ \\
\hline Saudi national & $\begin{array}{l}0.038 \\
(0.063)\end{array}$ & $\begin{array}{l}-0.034 \\
(0.060)\end{array}$ & $\begin{array}{l}-0.005 \\
(0.036)\end{array}$ \\
\hline Private sector employee & $\begin{array}{l}-0.074 \\
(0.050)\end{array}$ & $\begin{array}{l}0.064 \\
(0.047)\end{array}$ & $\begin{array}{l}0.009 \\
(0.028)\end{array}$ \\
\hline Retiree & $\begin{array}{l}0.052 \\
(0.145)\end{array}$ & $\begin{array}{l}-0.028 \\
(0.146)\end{array}$ & $\begin{array}{l}-0.024 \\
(0.094)\end{array}$ \\
\hline Self-employed & $\begin{array}{l}0.699 \\
(43.395)\end{array}$ & $\begin{array}{l}0.463 \\
(29.108)\end{array}$ & $\begin{array}{l}-1.162 \\
(72.503)\end{array}$ \\
\hline Student & $\begin{array}{l}0.117 * \\
(0.065)\end{array}$ & $\begin{array}{l}-0.113^{*} \\
(0.062)\end{array}$ & $\begin{array}{l}-0.004 \\
(0.039)\end{array}$ \\
\hline Unemployed & $\begin{array}{l}-0.004 \\
(0.068)\end{array}$ & $\begin{array}{l}0.003 \\
(0.065)\end{array}$ & $\begin{array}{l}0.000 \\
(0.038)\end{array}$ \\
\hline Observations & 950 & 950 & 950 \\
\hline
\end{tabular}

Notes: Standard errors in parentheses. ${ }^{* * *} p<0.01,{ }^{* *} p<0.05,{ }^{*} p<0.1$.

policy responses to safeguard the population's psychological wellbeing amidst the COVID-19 public health crisis.

The study found that about $40 \%$ of the KSA population had psychological distress. This result is analogous to the $40 \%$ found in Italy, ${ }^{20}$ and close to that found in France, which was that $38 \%$ of the public are distressed due to COVID-19. ${ }^{23}$ Iran has found that $59 \%$ of its population is distressed due to the pandemic, ${ }^{24}$ which is higher than has been found in this study. Therefore, this study's findings reveal that KSA has similar levels of COVID-19 distress as some countries, while remaining lower when compared to other countries, such as Iran.

Nevertheless, KSA's COVID-19 level of distress is, on average, high considering the proactive early pandemic control measures that KSA undertook in comparison to Italy and France, who had less time to prepare and implement effective measures. Hence, psychological distress remains one of the significant health problems in KSA during the pandemic. ${ }^{25}$ Moreover, there is a particular concern because certain groups were found to be more affected than others in this study. Across the entire sample of the KSA population, the results showed that health workers have an increased probability of becoming both mildly and severely distressed, due to COVID-19, compared to the rest of the population. These health practitioners are working in close contact with the people affected by the pandemic and, hence, are highly exposed to the risk of contracting the disease from their patients. ${ }^{26}$ Not only are the health workers distressed due to fear of infection but, also, the increased number of patients in healthcare facilities due to the pandemic has amplified the caseload per health worker and number of working hours. ${ }^{27}$

Across the age groups, the study found that older people are relatively less stressed compared with young people. This result supports similar evidence found in China. ${ }^{28}$ The reason behind this could be that older people can manage their stress due to better knowledge about the pandemic relative to the young. ${ }^{29}$ Another explanation could be that younger people experience the highest mental distress due to COVID-19 because of their high exposure to social media, ${ }^{30}$ which transmits a large amount of information about the pandemic, some of which is necessary, while some are disturbing. Previous evidence from KSA substantiates this finding by showing that the young, particularly those in undergraduate college levels, experience high distress due to internet addiction. ${ }^{31}$ Moreover, a study in Pakistan found that $82.8 \%$ of the population identified the internet as a major source of the panic that is generated about COVID-19 fears. ${ }^{32}$ Furthermore, the young also happen to be the group involved in the most outdoor activities, such as attending sports events that have been banned under lockdown due to the pandemic. As such, the young people need to adapt to new indoor ways of living that could be generating boredom and 
frustration. Moreover, previous evidence has revealed that prolonged quarantine restrictions generate fear and anxiety. $^{33}$

Females were more susceptible to distress relative to males. Similarly, recent studies in China and Italy that assessed psychological distress post the COVID-19 outbreak found that females were more likely to develop psychological distress, while males are less susceptible to post-traumatic distress in responding to stressful outbreaks. ${ }^{12,20}$ This finding could be attributed to gender differences in the hormonal response to stress. ${ }^{34}$ Young, Korszun ${ }^{35}$ substantiate this evidence that female hormones amplify the magnitude of stress responses within this group.

Private sector employees were found to be more distressed relative to government sector workers, which could be due to the variations in employment sector benefits in KSA. The government sector has greater job security relative to the private sector. ${ }^{36}$ In the event that the total economy lockdowns implemented due to the pandemic lead to loss of business, especially for non-essential services, private sector employees could lose their jobs, which is not the case for government employees, who have secure jobs relative to private sector workers. Therefore, it is not very surprising that private sector workers are more distressed than their public sector counterparts.

In the sample of health workers, the study found similar results to those of the full sample that older people and males are less likely to be distressed relative to the young and females, respectively. An additional result is that, amongst the health workers, frontline health workers face increased chances of severe distress relative to the rest of the health workers, which is consistent with the findings from Italy. ${ }^{20}$ Being the first-hand attendants of the pandemic in the health system exposes them to the largest risk of contracting the virus. As such, it is not surprising that their fears and psychological breakdowns are greater than the general public. However, the results showed that, amongst the health workers, students are less likely to be distressed. In KSA, students who are also health workers are those in their final year of their studies and are conducting internships. Since the lockdown in KSA, interns, together with other scholars, were asked to suspend lessons, which included their work. Hence, this action reduced their exposure to the pandemic and relieved them of their duties relative to the full-time employees in the health sector, which makes the students less likely to be distressed.
These results have implications for policy. Cases of psychological distress have been on the increase due to abrupt changes in lifestyle, such as school lockdowns and curfews. In China, these invasive actions were disruptive to people's lives. ${ }^{12}$ The resultant negative psychological impact of COVID-19 mitigation measures demand policy interventions to prevent the worsening of distress among Saudi Arabians. Thus, adequate research was needed to explore the measure of the pandemic's psychological effects on the community and the affected groups of people. ${ }^{37}$ The research findings of this paper will help in establishing both immediate actions and long-term strategic plans in managing psychological distress.

In the medium term, there is a need to improve monitoring and reporting of anxiety rates, depression and self-harm, especially amongst the highly affected groups such as healthcare workers and the younger population. The information will assist in targeting appropriate medical interventions to help the affected individuals. ${ }^{37}$ In addition, it is necessary to map the already existent psychological support and resources to be used in both treatment of and prevention of such effects. In the long term, the government needs to invest in identifying the root causes of the high rates of distress and anxiety amongst the already implemented COVD-19 prevention measures. In addition, there is a need to develop novel interventions that safeguard people's mental wellbeing, such as promoting prosocial behaviour, altruism and embracing psychosocial heightening online activities. ${ }^{37}$

\section{Study Limitations}

The study is not without its limitations. First, by using an online questionnaire, the study selects a population that has access to the internet, which might affect its sample's representativeness. Nevertheless, the study received data that encompassed all the regions of the kingdom, which might reduce the problem with regard to geographical coverage. Of course, the authors acknowledge that the technological selectivity and the unreliability of self-administered questionnaire issues are not completely settled. However, the online survey is the best possible case with the current need to maximise social distance under COVID-19 mitigation. Second, as the study uses cross-sectional data, it could not control for unobserved heterogeneity across the respondents. Therefore, the estimates should be interpreted with caution, as associations and not implying causation. Future research could perform a follow-up on our sample once the pandemic is over to form panel data and control for time-invariant unobserved heterogeneity. 


\section{Conclusion}

The COVID-19 pandemic has brought about unprecedented changes in human lives, which could lead to serious psychological distress if disregarded. Limiting such distress, therefore, relies on identifying the groups of people that are at the highest risk due to the pandemic. This study examined the factors that are associated with psychological distress during the COVID-19 pandemic in Saudi Arabia using cross-sectional data obtained from an online survey. The online survey has been useful as we are in the heat of the pandemic, where the traditional physical surveys are not allowed to prevent the spread of the virus. The study used descriptive analysis and logistical regressions to understand the important sociodemographic variables related to postCOVID-19 distress. The findings showed that being a health worker, a frontline health worker, a young person, a female and a private sector employee are related to distress in KSA. The study further argues that increased efforts in raising the public awareness of COVID-19 and providing supportive psychological programs and verified social networks, in both the immediate and long term, remain vital in mitigating the psychological distress amongst the affected Saudis. The results from KSA can be applied in designing policy response for the post-traumatic psychological disorders not only in KSA but also in the other Arabian Gulf countries that have similar backgrounds, culture and religion and are facing similar challenges.

\section{Data Sharing Statement}

The datasets generated and/or analysed during the current study are not publicly available due to privacy and confidentiality agreements as well as other restrictions, but are available from the corresponding author (MKA) on reasonable request.

\section{Author Contributions}

All authors made substantial contributions to conception and design, acquisition of data, or analysis and interpretation of data; took part in drafting the article or revising it critically for important intellectual content; gave final approval of the version to be published; and agree to be accountable for all aspects of the work.

\section{Funding}

This project was funded by the Deanship of Scientific Research (DSR) at King Abdulaziz University, Jeddah, under grant no. GCV19-8-1441. The funders had no role in study design, data collection and analysis, decision to publish, or preparation of the manuscript. The authors, therefore, acknowledge with thanks DSR for technical and financial support.

\section{Disclosure}

The authors declare no conflicts of interest.

\section{References}

1. Zhu N, Zhang D, Wang W, et al. A novel coronavirus from patients with pneumonia in China, 2019. N Engl J Med. 2020;382:727-733. doi:10.1056/NEJMoa2001017

2. WHO. Mental health and psychosocial considerations during the COVID-19 outbreak; 2020. Available from: https://www.who.int/ docs/default-source/coronaviruse/mental-health-considerations.pdf. Accessed May 9, 2020.

3. Suresh V. The 2019 novel corona virus outbreak-An institutional guideline. Indian J Anaesth. 2020;64(3):242. doi:10.4103/ija.IJA_104_20

4. WHO. WHO timeline - COVID-19; 2020. Available from: https:// www.who.int/news-room/detail/27-04-2020-who-timeline-covid -19. Accessed May 09, 2020.

5. Ramesh N, Siddaiah A, Joseph B. Tackling corona virus disease 2019 (COVID 19) in workplaces. Indian J Occup Environ Med. 2020;24 (1):16. doi:10.4103/ijoem.IJOEM_49_20

6. Cirrincione L, Plescia F, Ledda C, et al. COVID-19 pandemic: prevention and protection measures to be adopted at the workplace. Sustainability. 2020;12(9):3603. doi:10.3390/su12093603

7. Lau H, Khosrawipour V, Kocbach P, et al. The positive impact of lockdown in Wuhan on containing the COVID-19 outbreak in China. J Travel Med. 2020;27. doi:10.1093/jtm/taaa037

8. Brodeur A, Clark AE, Fleche S, Powdthavee N. Assessing the impact of the coronavirus lockdown on unhappiness, loneliness, and boredom using Google Trends. arXiv Preprint arXiv:200412129. 2020.

9. Zhang J, Lu H, Zeng H, et al. The differential psychological distress of populations affected by the COVID-19 pandemic. Brain Behav Immun. 2020;87:49-50. doi:10.1016/j.bbi.2020.04.031

10. Torales J, O’Higgins M, Castaldelli-Maia JM, Ventriglio A. The outbreak of COVID-19 coronavirus and its impact on global mental health. Int J Soc Psychiatr. 2020;66(4):317-320. doi:10.1177/0020764020915212

11. Brooks SK, Webster RK, Smith LE, et al. The psychological impact of quarantine and how to reduce it: rapid review of the evidence. Lancet. 2020;395:912-920. doi:10.1016/S0140-6736(20)30460-8

12. Qiu J, Shen B, Zhao M, Wang Z, Xie B, Xu Y. A nationwide survey of psychological distress among Chinese people in the COVID-19 epidemic: implications and policy recommendations. Gen Psychiatr. 2020;33(2):e100213. doi:10.1136/gpsych-2020-100213

13. Cascella M, Rajnik M, Cuomo A, Dulebohn SC, Di Napoli R. Features, evaluation and treatment coronavirus (COVID-19). In: Statpearls [Internet]. StatPearls Publishing; 2020.

14. Shigemura J, Ursano RJ, Morganstein JC, Kurosawa M, Benedek DM Public responses to the novel 2019 coronavirus (2019-nCoV) in Japan: mental health consequences and target populations. Psychiatr Clin Neurosci. 2020;74(4):281. doi:10.1111/pcn.12988

15. Bao Y, Sun Y, Meng S, Shi J, Lu L. 2019-nCoV epidemic: address mental health care to empower society. Lancet. 2020;395(10224) e37-e38. doi:10.1016/S0140-6736(20)30309-3

16. Sood S. Psychological effects of the Coronavirus disease-2019 pandemic. Res Human Med Educ. 2020;7:23-26.

17. Al-Hanawi MK, Alsharqi O, Almazrou S, Vaidya K. Healthcare finance in the Kingdom of Saudi Arabia: a qualitative study of householders' attitudes. Appl Health Econ Health Policy. 2018;16 (1):55-64. doi:10.1007/s40258-017-0353-7 
18. Arvidsdotter T, Marklund B, Kylén S, Taft C, Ekman I. Understanding persons with psychological distress in primary health care. Scand J Caring Sci. 2016;30(4):687-694. doi:10.1111/scs.12289

19. Fetters L, Tilson J. Evidence Based Physical Therapy. FA Davis; 2018.

20. Moccia L, Janiri D, Pepe M, et al. Affective temperament, attachment style, and the psychological impact of the COVID-19 outbreak: an early report on the Italian general population. Brain Behav Immun. 2020;87:75-79. doi:10.1016/j.bbi.2020.04.048

21. Menninger KA. Psychoses associated with influenza: i. general data: statistical analysis. J Am Med Assoc. 1919;72(4):235-241. doi:10.10 01/jama.1919.02610040001001

22. Fardin MA. COVID-19 and anxiety: a review of psychological impacts of infectious disease outbreaks. Arch Clin Infect Dis. 2020;15(COVID-19):e102779. doi:10.5812/archcid.102779

23. Chaix B, Delamon G, Guillemasse A, Brouard B, Bibault J-E. Psychological distress during the COVID-19 pandemic in France: a national assessment of at-risk populations. medRxiv. 2020.

24. Jahanshahi AA, Dinani MM, Madavani AN, Li J, Zhang SX. The distress of Iranian adults during the Covid-19 pandemic-More distressed than the Chinese and with different predictors. Brain Behav Immun. 2020;87:124-125. doi:10.1016/j.bbi.2020.04.081

25. Barry M, Ghonem L, Alsharidi A, et al. Coronavirus disease-2019 pandemic in the Kingdom of Saudi Arabia: mitigation measures and hospital preparedness. J Nat Sci Med. 2020;2.

26. Lu W, Wang H, Lin Y, Li L. Psychological status of medical workforce during the COVID-19 pandemic: a cross-sectional study. Psychiatry Res. 2020;288:112936. doi:10.1016/j.psychres.2020.11 2936

27. Verma S, Mythily S, Chan Y, Deslypere J, Teo E, Chong S. PostSARS psychological morbidity and stigma among general practitioners and traditional Chinese medicine practitioners in Singapore. Ann Acad Med Singapore. 2004;33(6):743-748.
28. Guo Q, Zheng Y, Shi J, et al. Immediate psychological distress in quarantined patients with COVID-19 and its association with peripheral inflammation: a mixed-method study. Brain Behav Immun. 2020. doi:10.1016/j.bbi.2020.05.038

29. Al-Hanawi MK, Angawi K, Alshareef N, et al. Knowledge, attitude and practice toward COVID-19 among the public in the Kingdom of Saudi Arabia: a cross-sectional study. Front Public Health. 2020;8:217. doi:10.3389/fpubh.2020.00217

30. Cheng C, Jun H, Liang B. Psychological health diathesis assessment system: a nationwide survey of resilient trait scale for Chinese adults. Stud Psychol Behav. 2014;12:735-742.

31. Hasan AA-H, Jaber AA. Prevalence of internet addiction, its association with psychological distress, coping strategies among undergraduate students. Nurse Educ Today. 2019;81:78-82. doi:10.1016/j. nedt.2019.07.004

32. Balkhi F, Nasir A, Zehra A, Riaz R. Psychological and behavioral response to the coronavirus (COVID-19) pandemic. Cureus. 2020;12(5).

33. Taghrir MH, Akbarialiabad H, Marzaleh MA. Efficacy of mass quarantine as leverage of health system governance during COVID-19 outbreak: a mini policy review. Arch Iran Med. 2020;23 (4):265-267. doi:10.34172/aim.2020.08

34. Sareen J, Erickson J, Medved MI, et al. Risk factors for post-injury mental health problems. Depress Anxiety. 2013;30(4):321-327. doi:10.1002/da.22077

35. Young E, Korszun A. Sex, trauma, stress hormones and depression. Mol Psychiatry. 2010;15(1):23-28. doi:10.1038/mp.2009.94

36. Alkhamis A, Cosgrove P, Mohamed G, Hassan A. The personal and workplace characteristics of uninsured expatriate males in Saudi Arabia. BMC Health Serv Res. 2017;17(1):56. doi:10.1186/s12913-017-1985-x

37. Holmes EA, O'Connor RC, Perry VH, et al. Multidisciplinary research priorities for the COVID-19 pandemic: a call for action for mental health science. Lancet Psychiatr. 2020;7(6):547-560. doi:10.1016/S2215-0366(20)30168-1
Risk Management and Healthcare Policy

\section{Publish your work in this journal}

Risk Management and Healthcare Policy is an international, peerreviewed, open access journal focusing on all aspects of public health, policy, and preventative measures to promote good health and improve morbidity and mortality in the population. The journal welcomes submitted papers covering original research, basic science, clinical \& epidemiological studies, reviews and evaluations,

\section{Dovepress}

guidelines, expert opinion and commentary, case reports and extended reports. The manuscript management system is completely online and includes a very quick and fair peer-review system, which is all easy to use. Visit http://www.dovepress.com/testimonials.php to read real quotes from published authors. 